\title{
A Changing Landscape of Gout: Comorbidity Matters
}

Gout is the most common inflammatory arthritis, with an increasing prevalence in many parts of the world ${ }^{1,2}$. Fewer studies have estimated the incidence of gout and its global trends. The Second and Third National Studies of Morbidity in General Practice in the United Kingdom estimated the respective gout incidence of 1.0 and 1.4 per 1000 person-years in the periods $1971-1975$ and $1981-1982^{3}$ while database-based research estimated an incidence of 1.19-1.80 per 1000 person-years in the period 1990-1999 and from 1.36-1.77 per 1000 person-years in the period $1997-2012^{1}$. Data from the Rochester Epidemiology project estimated an age- and sex-adjusted incidence of gout of 45 per 100,000 people in the period 1977-1978 and 62 per 100,000 people in 1995-1996 $6^{5}$. In this issue of The Journal, Elfishawi, et al also used data from the Rochester Epidemiology project to compare the incidence of gout between periods 1989-1992 and $2009-2010^{6}$. The incidence more than doubled, from 66.6 to 136.7 per 100,000 people. This study used the same cohort in Olmsted County, Minnesota, USA, and the same system of medical recording (for case identification) as the previous study by Arromdee, et $l^{5}$. They collectively provide serial measurements of gout incidence covering over 3 decades and document a tripling of gout incidence. Overall, data from the United Kingdom and the United States portrayed a similar pattern of accelerating gout occurrence.

How to explain this worrisome phenomenon? In general, a significant change in disease incidence implies a change of risk factors or population composition. Elfishawi, et al provide their interesting observations: a multifold increase in many associated comorbidities of gout and hyperuricemia ${ }^{6}$. For example, there was a 4-fold increase for diabetes, 3 -fold for renal diseases and hyperlipidemia, 50\% for obesity, and $30 \%$ for hypertension. A closer look at the data found that the vast majority of incident gout patients in 2009-2010 in Minnesota had at least 1 such comorbidity that is known to associate with hyperuricemia and subsequently, gout, while fewer patients diagnosed with gout in 1989-1992 had any of these comorbidities. However, data from the National Health and Nutrition Examination Survey described a more modest increase in the prevalence of hyperuricemia: from $19.1 \%$ in

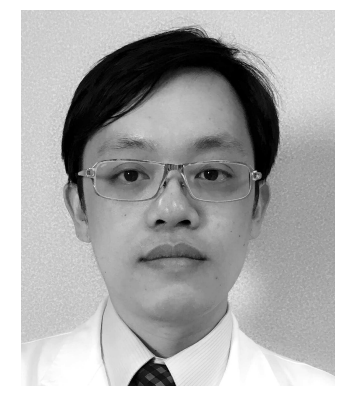

$1988-1994$ to $21.5 \%$ in $2007-2008^{7}$. Therefore, although hyperuricemia is the most important risk factor for gout, it alone cannot explain the substantial increase in gout incidence. Other mechanistic factors are required to explain the association between an increase in gout incidence and the increasing prevalence of associated comorbidities among these patients.

However, this study and previous evidence undoubtedly indicate a changing landscape of gout and that our strategy to manage gout must consider the high prevalence of comorbidities rather than treating them as arthritis alone. First, the initial assessment of incident gout patients should include a comorbidity checklist. Currently, the European League Against Rheumatism recommendations ${ }^{8}$, the British Society for Rheumatology ${ }^{9}$, and the American College of Rheumatology guidelines ${ }^{10}$ all recommend comorbidities that may contribute to or associate with hyperuricemia as part of an initial assessment of patients with gout. The comorbidity checklist, including obesity, metabolic syndrome, diabetes mellitus, hyperlipidemia, urolithiasis, and chronic kidney diseases, is roughly consistent with the comorbidities that occurred more commonly in newly diagnosed patients with gout, as reported by Elfishawi, et $a l^{6}$. Despite recent evidence indicating that gout is associated with a greater array of comorbidities ${ }^{11}$, it seems reasonable to consider the most common comorbidities that are also risk factors for major adverse cardiac events such as coronary heart diseases. Second, clinicians must consider the effects of short-term or longterm gout treatment on the associated comorbidities. For example, repeated use of nonsteroidal antiinflammatory drugs to control arthritis may be dangerous for patients at high risk for cardiovascular or renal diseases, while selected patients with heart failure may benefit from allopurinol ${ }^{12}$. Medications such as aspirin or thiazide diuretics may interfere with hyperuricemia control. These complex drug-disease interactions require careful consideration to maximize clinical benefits while minimizing risks. Third, comorbidities can be used as an indicator of prognosis to assist patient categorization and to identify high-risk patients. However, although gout is a well-accepted risk factor for

See Gout incidence and comorbidities, page 574

Personal non-commercial use only. The Journal of Rheumatology Copyright @ 2018 . All rights reserved. 
cardiovascular ${ }^{13}$ and renal diseases ${ }^{14}$ and is associated with a higher risk for mortality ${ }^{15}$, the effects of interaction between gout and comorbidities on the overall prognosis are still unclear. Nevertheless, gout patients with associated comorbidities should be considered high-risk individuals, and they need a thorough assessment and observation.

The study by Elfishawi, et al has raised questions that remain to be answered: First, is the increasing incidence of gout a unique problem in developed countries such as the United States, or is it an epi-phenomenon across the globe? The Global Burden of Disease 2010 study found no increase in global gout prevalence between 1990 and $2010^{16}$, which seems to contradict the results of Elfishawi, et $a l^{6}$. More studies are needed to harmonize these differences. Second, does the increased prevalence of comorbidities in incident gout patients imply a pathogenic link between these conditions? A recent metaanalysis summarizing studies investigating the association between urate levels and comorbidities concluded that a causal role of urate levels linked to comorbidities such as diabetes, hypertension, metabolic syndrome, and renal diseases has not been demonstrated by Mendelian randomization study (which eliminates confounding using genetic tools) with sufficient evidence, despite a strong support from epidemiological studies ${ }^{17}$. Third, should gout patients with comorbidities be managed differently from those with "primary" gout? How should they be categorized?

Elfishawi, et al demonstrated an increased incidence of gout in the past 2 decades in Olmsted County, but whether this finding can be generalized externally remains to be observed. The alarmingly high prevalence of associated comorbidities in newly diagnosed patients with gout reminds us that most gout patients are complicated, with many conditions that may have dire consequences. We still are not sure about the causative relationships between gout and associated comorbidities, but it is prudent to consider a comorbidity checklist for all newly diagnosed patients, and probably also for all patients with existing gout. Last, a research agenda to fully understand the global trends of gout incidence in other areas/countries and the occurrence of associated comorbidities and their effect on the clinical management of gout is warranted for better care of patients with gout.

\section{CHANG-FU KUO, MD, $\mathrm{PhD}$,}

Division of Rheumatology, Allergy and Immunology, Chang Gung Memorial Hospital, Taoyuan, Taiwan; and Division of Rheumatology, Orthopaedics and Dermatology, School of Medicine, University of Nottingham, Nottingham, UK.

Address correspondence to Dr. C.F. Kuo, Chang Gung Memorial Hospital, 5 Fu-Hsing St., Taoyuan, Taiwan 333; or Academic Rheumatology, Clinical Sciences Building, City Hospital, Nottingham, UK NG51PB. E-mail: zandis@gmail.com; zandis@adm.cgmh.org.tw

\section{REFERENCES}

1. Kuo CF, Grainge MJ, Mallen C, Zhang W, Doherty M. Rising burden of gout in the UK but continuing suboptimal management: a nationwide population study. Ann Rheum Dis 2015;74:661-7.

2. Kuo CF, Grainge MJ, See LC, Yu KH, Luo SF, Valdes AM, et al. Familial aggregation of gout and relative genetic and environmental contributions: a nationwide population study in Taiwan. Ann Rheum Dis 2015;74:369-74.

3. Stewart OJ, Silman AJ. Review of UK data on the rheumatic diseases - 4. Gout. Br J Rheumatol 1990;29:485-8.

4. Mikuls TR, Farrar JT, Bilker WB, Fernandes S, Schumacher HR Jr., Saag KG. Gout epidemiology: results from the UK General Practice Research Database, 1990-1999. Ann Rheum Dis 2005;64:267-72.

5. Arromdee E, Michet CJ, Crowson CS, O'Fallon WM, Gabriel SE. Epidemiology of gout: is the incidence rising? J Rheumatol 2002;29:2403-6.

6. Elfishawi M, Zleik N, Kvrgic Z, Michet Jr. CJ, Crowson CS, Matteson EL, et al. The rising incidence of gout and the increasing burden of comorbidities: a population-based study over 20 years. J Rheumatol 2018;45:574-9.

7. Zhu Y, Pandya BJ, Choi HK. Prevalence of gout and hyperuricemia in the US general population: the National Health and Nutrition Examination Survey 2007-2008. Arthritis Rheum 2011;63:3136-41.

8. Richette P, Doherty M, Pascual E, Barskova V, Becce F, Castaneda-Sanabria J, et al. 2016 updated EULAR evidence-based recommendations for the management of gout. Ann Rheum Dis 2017;76:29-42.

9. Hui M, Carr A, Cameron S, Davenport G, Doherty M, Forrester H, et al. The British Society for Rheumatology guideline for the management of gout. Rheumatology 2017;56:e1-e20.

10. Khanna D, Fitzgerald JD, Khanna PP, Bae S, Singh MK, Neogi T, et al. 2012 American College of Rheumatology guidelines for management of gout. Part 1: systematic nonpharmacologic and pharmacologic therapeutic approaches to hyperuricemia. Arthritis Care Res 2012;64:1431-46.

11. Kuo CF, Grainge MJ, Mallen C, Zhang W, Doherty M. Comorbidities in patients with gout prior to and following diagnosis: case-control study. Ann Rheum Dis 2016;75:210-7.

12. Thanassoulis G, Brophy JM, Richard H, Pilote L. Gout, allopurinol use, and heart failure outcomes. Arch Intern Med 2010; 170:1358-64.

13. Kuo CF, Yu KH, See LC, Chou IJ, Ko YS, Chang HC, et al. Risk of myocardial infarction among patients with gout: a nationwide population-based study. Rheumatology 2013;52:111-7.

14. Yu KH, Kuo CF, Luo SF, See LC, Chou IJ, Chang HC, et al. Risk of end-stage renal disease associated with gout: a nationwide population study. Arthritis Res Ther 2012;14:R83.

15. Kuo CF, See LC, Luo SF, Ko YS, Lin YS, Hwang JS, et al. Gout: an independent risk factor for all-cause and cardiovascular mortality. Rheumatology 2010;49:141-6.

16. Smith E, Hoy D, Cross M, Merriman TR, Vos T, Buchbinder R, et al. The global burden of gout: estimates from the Global Burden of Disease 2010 study. Ann Rheum Dis 2014;73:1470-6.

17. Li X, Meng X, Timofeeva M, Tzoulaki I, Tsilidis KK, Ioannidis JP, et al. Serum uric acid levels and multiple health outcomes: umbrella review of evidence from observational studies, randomised controlled trials, and Mendelian randomisation studies. BMJ 2017;357:j2376.

J Rheumatol 2018;45:454-5; doi:10.3899/jrheum.171446 